\title{
ACRYLAMIDE IN FRENCH FRIES PREPARED IN AT HOME AND FAST FOOD CONDITIONS
}

\author{
Alina Cristina Adascălului ${ }^{1}$, Mioara Negoiță ${ }^{1 *}$, Adriana Laura Mihai ${ }^{1}$, Gabriela-Andreea Horneț ${ }^{1}$ \\ ${ }^{1}$ National Research \& Development Institute for Food Bioresources, IBA Bucharest, Chromatography Department, 6 \\ Dinu Vintilă Street, District 2, 021102 , Bucharest, Romania
}

Current Trends in

Natural Sciences

\begin{abstract}
French fries, prepared either at home or in fast food restaurants, are one of the most desired dishes of Romanians and the main contributors to the intake of acrylamide through the diet. The aim of this study was to investigate how the frying in at home and fast food conditions influences the acrylamide level of French fries and to establish a correlation between acrylamide content and the color parameters. Potatoes from the Queen Anne variety and two types of oil (sunflower, palm) were used. Frying in at home conditions was realized in a pan in sunflower and palm oils $\left(103^{\circ} \mathrm{C}\right.$ for 13-15 minutes) and frying in fast food conditions was performed in a fryer using only palm oil (170 ${ }^{\circ} \mathrm{C}$ for 11 minutes). Determination of acrylamide was achieved fallowing the GC-MS/MS method. The level of acrylamide in French fries fried in at home conditions showed higher acrylamide content when the sunflower oil was used $(764.58 \mu \mathrm{g} / \mathrm{kg})$ compared to the samples fried in palm oil $(541.65 \mu \mathrm{g} / \mathrm{kg})$. Also, a variation between the two types of frying was observed when using palm oil and a lower acrylamide level was obtained for French fries fried in at home conditions $(541.65 \mu \mathrm{g} / \mathrm{kg})$ than for potatoes fried in fast food conditions $(684.37 \mu \mathrm{g} / \mathrm{kg})$. For all the samples analyzed the acrylamide content exceeded the benchmark level of $500 \mu \mathrm{g} / \mathrm{kg}$ set by the Commission Regulation (EU) $2017 / 2158$. Linear correlations between acrylamide levels, expressed in \% d.m., and the color parameters ( $L^{*}, a^{*}$ and $\left.b^{*}\right)$ were found: as the level of acrylamide increased, the parameters $L^{*}$ and $b^{*}\left(R^{2}=0.80\right)$ decreased, and $a^{*}$ increased $\left(R^{2}=\right.$ 0.68).
\end{abstract}

Keywords: acrylamide, French fries, GC-MS/MS-SPE

\section{INTRODUCTION}

Acrylamide is a chemical process contaminant that is formed when food products rich in carbohydrates are subjected to a processing temperature higher than $120^{\circ} \mathrm{C}$ (Pedreschi, 2007). One way of acrylamide formation is the Maillard reaction that takes place between asparagine and reducing sugars, while another way is the lipid oxidation.

Acrylamide is one of the main contaminants in food products having the potential to increase the risk of developing cancer for consumers from all age groups.

Among the foods in which acrylamide is found, bread and derived products, pastries, coffee, but also different products derived from potato (French fries, chips) are the most important.

Potato products which are baked or fried have high levels of acrylamide (Tareke et al., 2000; Weisshaar, 2004), which are associated with the precursors found in large quantities in the potato tubers. Medeiros Vinci et al. (2011) emphasizes that the variation of the chemical composition of 
the potato will generally depend on several aspects: variety, agricultural practice, maturity at harvest, storage history.

Several guidelines who give specific recommendation for acrylamide mitigations in potato-based products were investigated. These included the code of practice (Codex Alimentarius, 2009), the FDA report (FDA, 2016), the EU Regulation 2017/2158 (EC, 2017), the acrylamide toolbox (FDE, 2019). The Commission Regulation (EU) 2017/2158 of 20 November 2017 provides the benchmark level for the main group categories of food products. For French fries, the benchmark level settled was $500 \mu \mathrm{g} / \mathrm{kg}$.

In the frying process the oil has two purposes, a heating medium and as ingredient that produces calorific products. Most of the time, frying generates a structure that has a dehydrated and crunchy outer layer and a moist or cooked region (Pedreschi and Moyano, 2005; Pedreschi, 2009).

Sunflower and palm oils are used in general for potatoes frying. Each type of oil has distinctive characteristics and acts different when reach the smoke point.

The sunflower oil is the most popular oil used in Romanian households. Compared to palm oil the sunflower oil has higher content of unsaturated fatty acids, it is more susceptible to oxidation and generates higher acrylamide concentration when it is used for cooking.

Palazoglu and Gokmen (2008) concluded that acrylamide forms at the surface and in near-surface region of the French fries because of the high temperature used at frying.

Frying by simulating at home and fast food conditions was investigated by many researchers. Romani et al. (2008) simulated the at home conditions and studied the time and temperature effect over acrylamide formation, the moisture, texture and the changing color of the French fries obtained from raw potatoes. It was also investigated the content of oil used at frying. Mesias et al. (2018) found that French fries prepared in Spanish homes had an acrylamide content two times higher than the average estimation given by the EFSA report for this food category.

Acrylamide from French fries prepared in food service establishments who operate under one trade mark or commercial license was studied by Mesias et al. (2019). The same study concluded that even if the potatoes were prepared in a fast food system, they give variation in acrylamide content, explained by the characteristics of the potatoes intended for frying, the frying conditions or the implication of human behavior to set the end point of frying.

Therefore, this investigation aimed to study the influence of the frying in at home and fast food conditions on the acrylamide level formed in French fries and to establish a correlation between acrylamide content of end products and the color parameters.

\section{MATERIALS AND METHODS}

\section{Chemicals, reagents and standards}

Native acrylamide (min. 99\% purity) obtained from Restek (Benner Circle, Bellefonte, USA) and internal standard (IS) of labeled acrylamide $\left(1,2,3-{ }^{13} \mathrm{C}\right.$, min. $99 \%$ purity) purchased from Cambridge Isotope Laboratories (Andover, MA, USA) were used. For this study, chemicals, reagents and solvents used were of analytical grade. Extraction SPE cartridges were Isolute ${ }^{\circledR}$ Multimode $(1000 \mathrm{mg}, 6 \mathrm{~mL})$ and Isolute ${ }^{\circledR} \mathrm{ENV}^{+}(500 \mathrm{mg}, 6 \mathrm{~mL})$, both supplied by Biotage (Uppsala, Sweden).

\section{Samples}

Potatoes from Queen Anne variety purchased from a local supermarket from Bucharest, Romania were used. On the label the producer declared that potatoes are „special for frying”. 
The edible vegetable fats used were sunflower oil and refined non-hydrogenated palm oil who were purchased from the same supermarket.

\section{Sample preparation}

All the potatoes samples were hand peeled, washed, cut ( $9 \mathrm{~mm} \times 9 \mathrm{~mm}$ dimension), rinsed in tap water and let to dry on absorbent paper. For this experiment, samples were fried simulating both of at home and fast food conditions. For frying in at home conditions a pan was used, while for frying in fast food conditions a fryer was used.

Frying the potatoes in at home conditions was realized with the constant and proper maintenance of stove flame throughout the entire process. The samples were fried using sunflower oil and palm oil, having a potato:oil ratio of 1:0.5 (w/w). The mean frying temperature was $103^{\circ} \mathrm{C}$ and the frying time was between 13 - 15 minutes.

Frying by simulating the conditions in a fast food was performed only in palm oil. The oil was weighted and transferred in the fryer up to the low level, then the fryer was gradually heated at $170^{\circ} \mathrm{C}$, and maintained at this temperature for $30 \mathrm{~min}$ before frying the potatoes samples. The frying temperature was under $175^{\circ} \mathrm{C}$ as Commission Regulation (EU) 2017/2158 recommends. Potatoes were fried for 11 minutes in a temperature-controlled fryer with two unites of customized $4 \mathrm{~L}$ capacity stainless (Hendi Blue Line) and having the potato:oil ratio (w/w) of 1:4. After frying, potatoes were left to lose the oil in excess. After samples were cooled, it were grounded and homogenized in a laboratory mixer (Büchi, Labortechnik AG, Germany). Until analysis, samples were kept in the freezer at $-20^{\circ} \mathrm{C}$.

\section{Acrylamide determination by GC-MS/MS}

A solid-phase extraction technique was used to extract acrylamide while the quantification was performed with a gas chromatograph in tandem with mass spectrometer. The method was previously described by Negoiță et al. (2020). For acrylamide detection, two calibration curves (in the range $0.05-3 \mathrm{mg} / \mathrm{L}$ ) were realized, which had the correlation coefficients higher than 0.999 . The method presented a good recovery (between 85.64 and 109.22\%) and the limit of detection (LOD) for the samples analyzed was $10.29 \mu \mathrm{g} / \mathrm{kg}$, while the limit of quantification (LOQ) was $30.87 \mu \mathrm{g} / \mathrm{kg}$. The acrylamide content of French fries samples analyzed was expressed in $\mu \mathrm{g} / \mathrm{kg}$ and also in $\mu \mathrm{g} / \%$ dry matter (d.m.).

\section{Determination of moisture content}

The determination of moisture content was realized based on an official AOAC method (AOAC, 1995). The analyze was realized in duplicate and the results were expressed as mean \pm standard deviation (SD).

\section{Color determination}

Color measurements of the French fries samples were performed using a Konica Minolta spectrophotometer (Universal Software V4.01 Miniscan XE Plus). For all the samples analyzed 10 measurements of the color parameters $L^{*}$ (lightness), $a^{*}$ (negative values indicate green and positive values indicate red), and $b^{*}$ (negative values indicate blue and positive values indicate yellow) were realized. Results were expressed as mean \pm SD. 


\section{Current Trends in Natural Sciences}

Vol. 10, Issue 20, pp. 06-12, 2021

https://doi.org/10.47068/ctns.2021.v10i20.001

Current Trends in Natural Sciences (on-line)

\section{Statistical analysis}

For acrylamide determination, the analyses were realized in duplicate, using the average of the results for interpretation. The content obtained was expressed in $\mu \mathrm{g} / \mathrm{kg}$ and also in $\mu \mathrm{g} / \% \mathrm{~d} . \mathrm{m}$. The results were expressed in $\%$ for the moisture content.

\section{RESULTS AND DISCUSSIONS}

\section{Acrylamide content}

For this study the influence of the type of frying conditions on the acrylamide concentrations of French fries was investigated. The moisture and acrylamide content were determined for all the samples analyzed (Table 1).

Table 1. Moisture and acrylamide content of the French fries samples

\begin{tabular}{|l|c|c|c|c|}
\hline Experimental variants & Vegetable oil & \multirow{2}{*}{\begin{tabular}{c} 
Moisture \\
\cline { 4 - 5 }
\end{tabular}} & & \multicolumn{2}{|c|}{ Acrylamide } \\
\cline { 4 - 5 } at home conditions, $\%$ & $\boldsymbol{\mu g} / \mathbf{k g}$ & $\boldsymbol{\mu g} / \mathbf{\%}$ d.m. \\
\cline { 4 - 5 } & sunflower & $50.17 \pm 0.59$ & $764.58 \pm 2.72$ & 153.44 \\
\hline fast food conditions (V2) & palm & $53.27 \pm 0.71$ & $541.65 \pm 2.49$ & 115.91 \\
\hline
\end{tabular}

For at home conditions, the samples analyzed showed a higher acrylamide content when frying in sunflower oil $(764.58 \mu \mathrm{g} / \mathrm{kg})$ compared to palm oil $(541.65 \mu \mathrm{g} / \mathrm{kg})$. This can be the result of the fact that the fatty acid composition of the oils used at frying influences the acrylamide content of the product, a higher content of unsaturated fatty acid from sunflower oil determining a higher acrylamide level than palm oil (Abd Razak et al., 2021). Also, our results are in accordance with the findings of Kuek et al. (2020), a higher level of acrylamide being found in French fries fried in sunflower oil compared to the ones fried in palm oil.

A variation between the two types of frying was also observed when palm oil was used. A lower acrylamide level was obtained for French fries fried in at home conditions $(541.65 \mu \mathrm{g} / \mathrm{kg})$ than for French fries fried in fast food conditions $(684.37 \mu \mathrm{g} / \mathrm{kg})$. This fact can be explained by the higher temperature of frying in the fast food system than in at home model.

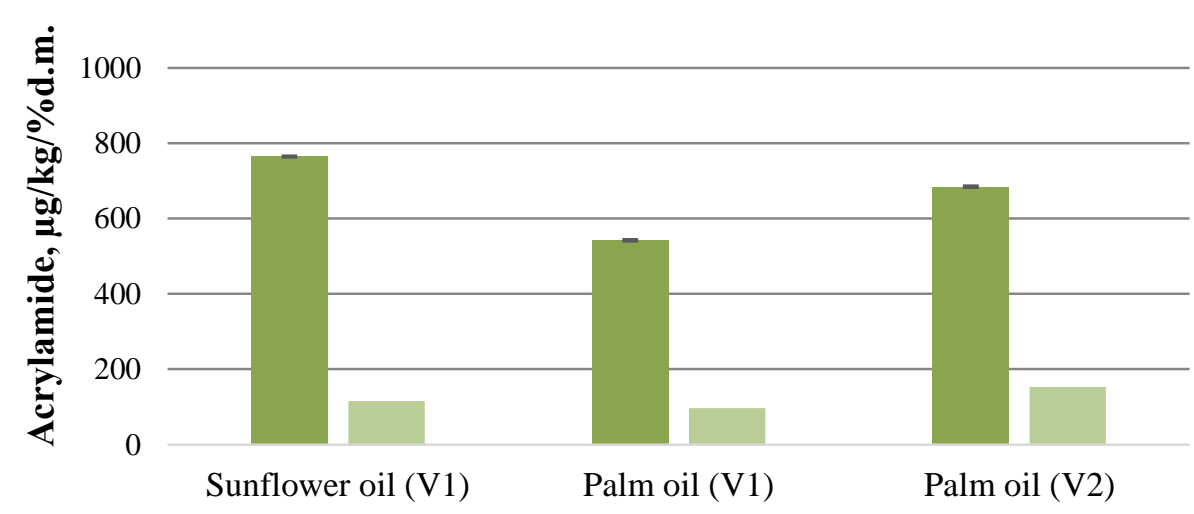

Figure 1. Variation of acrylamide content of potatoes fried in at home (V1)/fast food (V2) conditions

As it can be seen in table 1, the acrylamide content exceeded the benchmark level of $500 \mu \mathrm{g} / \mathrm{kg}$ set 


\section{Current Trends in Natural Sciences}

Vol. 10, Issue 20, pp. 06-12, 2021

https://doi.org/10.47068/ctns.2021.v10i20.001

Current Trends in Natural Sciences (on-line)

by the Commission Regulation (EU) 2017/2158 for all the samples of French fries.

Moisture content of the samples ranged between 29.45 and $53.27 \%$. Saguy and Dana (2003) reported up to $38 \%$ moisture content of French fries, while Mesias et al. (2019) stated that moisture content of French fries that came from restaurants was $45.83 \%$. Based on moisture content, the acrylamide level was also calculated and expressed in $\mu \mathrm{g} / 100 \mathrm{~g} \mathrm{~d} . \mathrm{m}$. When expressing the acrylamide content in $\mu \mathrm{g} / \% \mathrm{~d}$.m. results show a higher acrylamide content $(153.44 \mu \mathrm{g} / \% \mathrm{~d} . \mathrm{m}$.) when frying potatoes in sunflower oil compared to French fries fried in palm oil $(97 \div 115.91 \mu \mathrm{g} / \%$ d.m.)(Figure 1).

\section{Color parameters}

The Maillard reaction also known as browning process of food products which occurs when they reach a certain cooking temperature, is directly correlated with the acrylamide content of food products. The Commission Regulation (EU) 2017/2158 recommended that potatoes have to be cooked until a golden yellow color of the finished product, and not to cross that line in order to form a lower level of acrylamide.
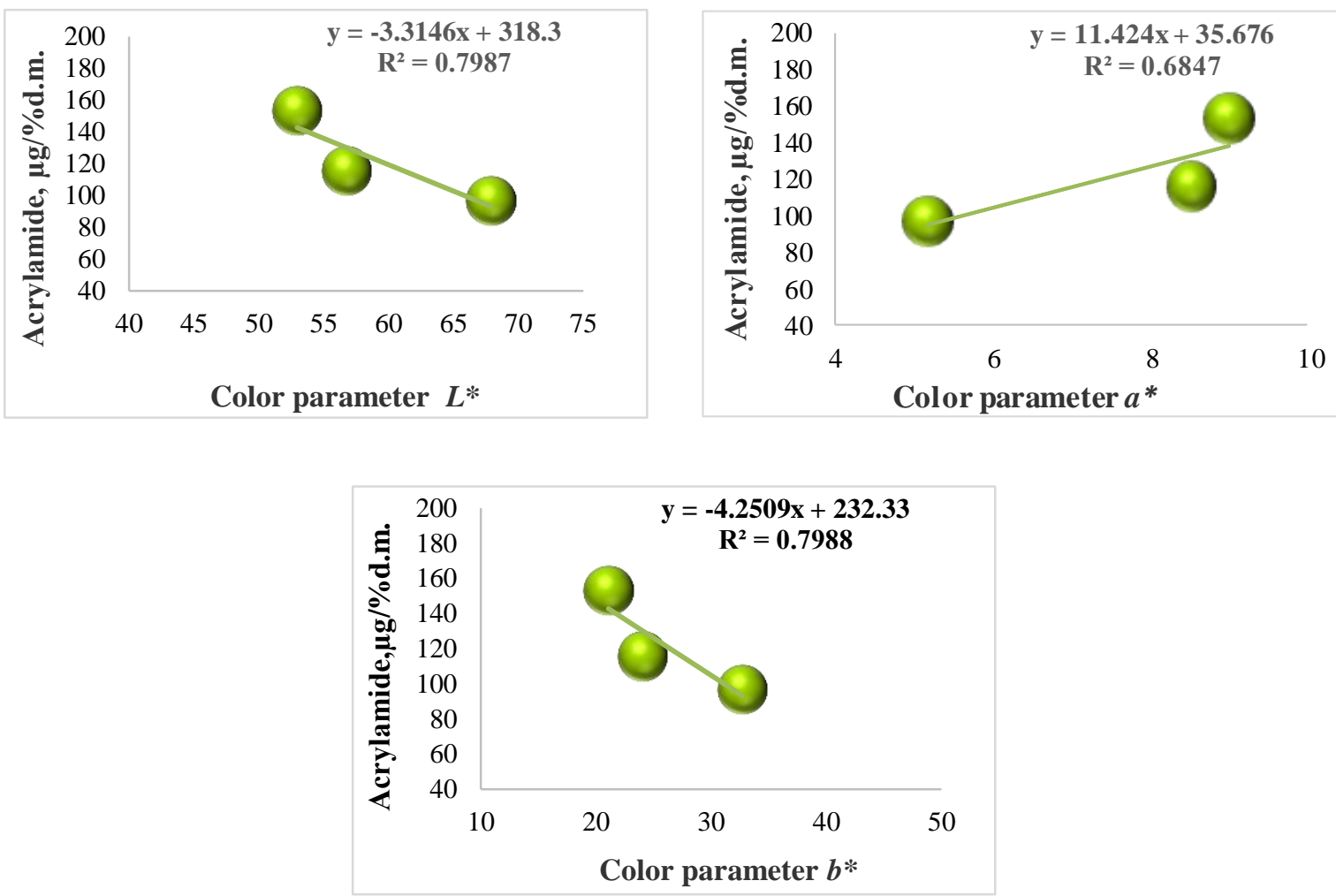

Figure 2. Variation of acrylamide content ( $\mu \mathrm{g} / \%$ d.m.) and color parameters of French fries samples

The CIELab colour parameters were evaluated and correlations were found between the acrylamide content expressed in dry matter and the color parameters $\left(L^{*}, a^{*}, b^{*}\right)$.

When the $L^{*}$ and $b^{*}$ parameters decreased, the concentration of acrylamide increased. This negative correlation is in accordance with the findings of Mesias et al. (2020) who also reported that the 


\section{Current Trends in Natural Sciences}

Vol. 10, Issue 20, pp. 06-12, 2021

https://doi.org/10.47068/ctns.2021.v10i20.001

Current Trends in Natural Sciences (on-line)

ISSN: 2284-953X

Current Trends in Natural Sciences (CD-Rom)

ISSN: 2284-9521

ISSN-L: 2284-9521

ISSN-L: 2284-9521

acrylamide concentration gets higher as the luminosity in the fried potatoes gets lower.

Color is one critical parameter which dictates when is the end-point of frying.

As it can be seen in figure 2, it was achieved a positive correlation between the acrylamide concentration and the color parameter $a^{*}$ (the longer the frying time was, the potatoes got browner, the acrylamide concentration and the $a^{*}$ parameter increased). Our result is sustained by the literature studies since this parameter is a useful, handy and easy to use tool in the formation of fried potatoes (Pedreschi et al., 2006; Pedreschi 2007; Mesias et al., 2018).

\section{CONCLUSIONS}

The results of this study showed that the frying in at home and fast food conditions influences the acrylamide level of French fries.

The highest acrylamide content was obtained when potatoes were fried in sunflower oil (764.58 $\mu \mathrm{g} / \mathrm{kg}$ ). When palm oil was used for frying potatoes, a higher acrylamide level was obtained for French fries fried in fast food conditions $(684.37 \mu \mathrm{g} / \mathrm{kg})$ compared to the ones fried in at home conditions $(541.65 \mu \mathrm{g} / \mathrm{kg})$.

Correlation between acrylamide content of the samples and the color parameters $L^{*}, a^{*}, b^{*}$ were achieved.

\section{ACKNOWLEDGEMENTS}

This study was achieved through Core Programme (PN 19 02), with the support of the Ministry of Research and Innovation (MCI), contract 22N/2019, project PN 19020301.

\section{REFERENCES}

Abd Razak, R., Tarmizi, A.H.A., Kuntom, A., Sanny, M., Ismail, I.S. (2021). Intermittent frying effect on French fries in palm olein, sunflower, soybean and canola oils on quality indices, 3-monochloropropane-1,2-diol esters (3MCPDE), glycidyl esters (GE) and acrylamide contents. Food Control, 124, 107887.

Association of Official Analytical Chemists. (1990). Moisture in Animal Feed. In 15th eds, Official Methods of Analysis (Vol. 930.15). Gaithersburg: AOAC, MD.

Codex Alimentarius. (2009). Code of practice for the reduction of acrylamide in foods. CAC/RCP 67-2009. Available from: http://www.fao.org/fao-who-codexalimentarius/news-and-events/news-details/en/c/469042/

Commission Regulation (EU) 2017/2158 of 20 November 2017 establishing mitigation measures and benchmark levels for the reduction of the presence of acrylamide in food. Available from: https://eurlex.europa.eu/eli/reg/2017/2158/oj

European Food Safety Authority (EFSA). (2015). Scientific opinion on acrylamide in food. EFSA Panel on contaminants in the food chain (CONTAM). EFSA Journal. 13(6):4104. Available from: https://www.efsa.europa.eu/en/efsajournal/pub/4104

FDA (Food and Drug Administration). (2016). Guidance for industry acrylamide in foods. Available from: https:/www.fda.gov/regulatory-information/search-fda-guidance-documents/guidance-industry-acrylamide-foods

FDE (Food Drink Europe). (2019). The acrylamide toolbox. Available from: https://www.fooddrinkeurope.eu/uploads/publications_documents/FoodDrinkEurope_Acrylamide_Toolbox_2019. pdf

Kuek, S.L., Tarmizi, A.H.A., Razak, R.A., Jinap, S., Norliza, S., Sanny, M. (2020). Contribution of lipid towards acrylamide formation during intermittent frying of French fries. Food Control, 118, 107430.

Medeiros Vinci, R., Mestdagh, F., Van Poucke, C., Kerkaert, B., de Muer, N., Denon, Q. (2011). Implementation of acrylamide mitigation strategies on industrial production of French fries: Challenges and pitfalls. Journal of Agricultural and Food Chemistry, 59, 898-906.

Mesias, M., Delgado-Andrade, C., Holgado, F., Morales, J. (2018). Acrylamide content in French fries prepared in households: A pilot study in Spanish homes. Food Chem., 260, 44-52.

Mesias, M., Delgado-Andrade, C., Holgado, F., Morales, J. (2019). Acrylamide content in French fries prepared in food service establisments. Food Science and Technology, 100, 83-91. 


\section{Current Trends in Natural Sciences}

Vol. 10, Issue 20, pp. 06-12, 2021

https://doi.org/10.47068/ctns.2021.v10i20.001

Current Trends in Natural Sciences (on-line)

Mesias, M., Delgado-Andrade, C., Holgado, F., Morales, J. (2020). Acrylamide in French fries prepared at primary school canteens. Food Funct., 11, 1489-1497

Negoiță, M., Mihai, A.L., Horneț, G.A., Duță, D.E. (2020). Development of SPE clean-up procedure for acrylamide determination from potato-based products by GC-MS/MS. DE GRUYTER. Open Agriculture, 5, 305-316.

Palazoglu, T.K., Gokmen, V. (2008). Development and experimental validation of a frying model to estimate acrylamide levels in French fries. Journal of Food Science, 73, E109-E114.

Pedreschi, F. (2007). The canon potato science: 49. Acrylamide. Potato Res, 50, 411-413.

Pedreschi, F. (2009). Fried and dehydrated potato products. In S. Jaspreet, \& K. Lovedeep, eds, Advances in potato chemistry and technology (pp. 319-337). San Diego: Academic Press.

Pedreschi, F., Kaack K., Granby K. (2006). Acrylamide content and color development in fried potato strips. Food Res. Int., 39, 40-46.

Pedreschi, F., Moyano, P. (2005). Effect of pre-drying on texture and oil uptake of potato chips. LWT-Food Science and Technology, 38, 599-604.

Romani, S., Bacchiocca, M., Rocculi, P., Dalla Rosa M. (2008). Effect of frying time on acrylamide content and quality aspects of French fries. Eur. Food. Res. Technol, 226, 555-560.

Saguy, I., Dana, D. (2003). Integrated approach to deep fat frying: Engineering, nutrition, health and consumer aspects. Journal of Food Engineering, 56, 143-152.

Tareke, E., Rydberg, P., Karlsson, P., Tornqvist, M., Eriksson, S. (2000). Acrylamide - a cooking carcinogen?. Chem Res Toxicol, 13, 517-522.

Weisshaar, R. (2004). Acrylamide in heated potato products-analytics and formation routes. Eur J Lipid Sci Technol, 106, 786-792. 